\title{
Avaliação do potencial imunoestimulante da Carboximetil-glucana de Saccharomyces cerevisiae em frangos de corte (Gallus domesticus)
}

\author{
Evaluation of potential immunostimulant of the Carboxymethyl- \\ glucan from Saccharomyces cerevisiae in poultry (Gallus domesticus)
}

\author{
Fernanda Patrícia Brito Darpossolo ${ }^{1 a^{*}}$; Leonardo Raffa Quintana ${ }^{1 \mathrm{~b}}$; \\ Marciane Magnani ${ }^{1 c}$; Alexandre $\mathrm{Oba}^{2}$; Emerson José Venâncio ${ }^{3}$; \\ Raul Jorge Hernan Castro-Goméz ${ }^{1 \mathrm{~d}}$
}

\begin{abstract}
Resumo
A carboximetilglucana (CMG) é uma molécula solúvel, composta de resíduos de glicopiranosil unidos em $\beta(1-3)$ e $\beta(1-6)$, que possui a capacidade de ativar o sistema imune do hospedeiro. O objetivo do presente estudo foi avaliar as características produtivas e imunológicas de 192 frangos de corte (Gallus domesticus) da linhagem COBB, que receberam rações contendo $0 \%, 0,025 \%, 0,050 \%$ e $0,075 \%$ de CMG de Saccharomyces cerevisiae adicionada em farinha de milho. Todas as aves foram imunizadas contra a doença de Newcastle e, em cada tratamento, 3 aves escolhidas aleatoriamente receberam CMG intramuscular no $3^{\circ}, 7^{\circ}$ e $14^{\circ}$ dia. Foram avaliados o desempenho animal, o desenvolvimento da bursa de Fabricius e lâminas histológicas do intestino delgado, além do número de células fagocíticas no sangue e níveis de anticorpos no soro. Os resultados mostraram diferença no ganho de peso e consumo de ração das aves que consumiram a CMG no período de 1 a 21 dias. O peso relativo da bursa de Fabricius aumentou nas aves suplementadas com 0,025 e $0,050 \%$ de CMG. O número de células fagocíticas e os níveis de anticorpos totais dos frangos de corte, aos 21 dias de idade foram maiores nas aves que receberam CMG na ração. Para os animais que receberam CMG via intramuscular foi observado aumento no título dos anticorpos específicos para Newcastle.

Palavras-chave: $\beta$-glucana, aves de corte, atividade imunomodulatória, levedura
\end{abstract}

\begin{abstract}
The carboxymethylglucan (CMG) is a soluble molecule, composed of glucopyranosyl linked by $\beta(1-3)$ e $\beta(1-6)$, which can activate the immune system of the host. The purpose of this study was evaluate the productive and immunological characteristics of 192 poultry (Gallus domesticus) COBB line which received feds containing $0 \%, 0,025 \%, 0,050 \%$ e $0,075 \%$ of CMG from Saccharomyces cerevisiae added in corn flour. All poultry were immunized against Newcastle disease and at each treatment 3 poultries randomly chosen received CMG intramuscular at 3, 7 and 14 days. It was evaluated the animal performance, development of the bursa of Fabricius, histological slides of the small intestine, counts of phagocytes cells in blood and levels of antibodies in serum. The results showed difference in weight
\end{abstract}

\footnotetext{
la Trabalho de Conclusão de Curso apresentado pelo primeiro autor ao Curso de Ciências Biológicas do Centro de Ciências da Saúde da Universidade Estadual de Londrina (UEL), atualmente mestranda em Ciência de Alimentos, Departamento de Ciência e Tecnologia de Alimentos (DCTA), UEL. Campus Universitário; CP 6001; CEP 86051-970. E-mail: ferdarpossolo@hotmail. com

${ }^{1 b}$ Mestre em Ciência de Alimentos, ${ }^{1 c}$ Doutoranda em Ciência de Alimentos, ${ }^{1 \mathrm{~d}}$ Prof. Titular, Departamento Ciência e Tecnologia de Alimentos, Centro de Ciências Agrárias, Universidade Estadual de Londrina (UEL).

2 Prof. Adjunto do Departamento de Ciências Agrárias, Centro de Ciências Agrárias, UEL. E-mail: oba@uel.br

3 Prof. Adjunto do Departamento de Ciências Patológicas, Centro de Ciências Biológicas, UEL. E-mail: emersonj@uel.br

* Autor para correspondência
} 
gain and consumption of feed to poultry that consumed CMG at 1 to 21 days. Fabricius bursa relative weight increased in poultry supplemented with 0,025 e $0,050 \%$ of CMG. The phagocytic cells number and total levels of antibodies found in poultry at 21 days were higher in those that received CMG in the diet. For the animals that received intramuscular CMG was observed increase of antibodies specific to Newcastle.

Key words: $\beta$-glucan, broiler chicken, immunomodulatory activities, yeasts

\section{Introdução}

Atualmente, o Brasil é o terceiro produtor e o maior exportador mundial de carne de frango (ABPEF, 2009) o que implica em atender as exigências dos consumidores internos e externos, tanto no que se refere à sanidade avícola, quanto à qualidade dos alimentos.

Conforme Edqvist e Pedersen (2002) o uso de antibióticos como aditivos promotores de crescimento na avicultura vêm sendo bastante questionado. Existe uma forte tendência em banir o uso dos antimicrobianos na produção animal, embasada na alegação de que alguns desses aditivos são semelhantes aos utilizados para terapia humana, o que poderia induzir, por pressão seletiva, a emergência de bactérias patogênicas multirresistentes. Diante deste cenário, países exportadores, como o Brasil, são forçados a adequar sua produção avícola buscando alternativas ao uso dessas drogas como aditivos. Neste contexto, Dionizio et al. (2002) relataram que a preocupação com o bem-estar e segurança animal na cadeia de produção de carne, aliada à necessidade de produtividade elevada impõe a busca de alternativas para a substituição dos antibióticos usados como promotores de crescimento, sem qualquer comprometimento ou aumento de custo da produção. Uma alternativa para substituição dos antibióticos é o emprego de imunoestimulantes não-específicos, como promotores de crescimento indireto, pois são eficientes no aumento da imunocompetência e da resistênciaa doenças. Além disso, imunoestimulantes não deixam resíduos na carcaça animal e no meio ambiente, e não provocam resistência cruzada em humanos (SILVA et al., 2000).
As $\beta$-glucanas são polímeros de glicose, componentes estruturais da parede celular de leveduras, que possuem a capacidade de atuar como estimulantes daatividadeimunológicanohospedeiro. A ativação do sistema imune pelas $\beta$-glucanas pode ser através das células imunocompetentes e ou seus mediadores químicos (BROWN; GORDON, 2003; KO; LIN, 2004; KIM et al., 2006).

Estudos realizados utilizando polissacarídeos, purificados ou não, na tentativa de substituir os antibióticos na avicultura, e os resultados observados são promissores (FUINI, 2001; GUO; ALI, QURESHI, 2003; MACHADO et al., 2007). Entre os aditivos estudados, a Carboximetilglucana (CMG) pode ser uma importante alternativa devido a sua capacidade de ativar de forma não específica os componentes humoral e celular do sistema imune do hospedeiro (TZIANABOS, 2000). A CMG é obtida através da solubilização da $\beta$-glucana, que em Saccharomyces cerevisiae é composta de resíduos de glicopiranosil com ligações $\beta-1,3$ e, em menor número e ramificações ligadas em $\beta-1,6$ (KLIS et al., 2002). Em frangos de corte sabe-se que a CMG pode realçar a resposta imune celular através da modulação dos macrófagos (CHENG et al., 2004). O objetivo deste estudo foi avaliar as características produtivas e imunológicas de frangos de corte, da linhagem $\mathrm{COBB}$, alimentados com dietas contendo diferentes níveis de $\mathrm{CMG}$, derivada de $\beta$-glucana insolúvel extraída da parede celular da levedura de panificação $S$. cerevisiae. 


\section{Material e Métodos}

\section{Obtenção da Carboximetilglucana (CMG)}

ACMG foi obtida de $\beta$-glucana insolúvel extraída da parede celular de $S$. cerevisiae. A autólise da massa de levedura, comercializada como fermento fresco, foi realizada em suspensão $25 \%(\mathrm{p} / \mathrm{p}), \mathrm{pH}$ 5.5 , à $55^{\circ} \mathrm{C}$ por $24 \mathrm{~h}$. Posteriormente, o material foi centrifugado a 5000rpm durante 10 minutos, o sobrenadante descartado e a $\beta$-glucana insolúvel extraída por tratamento com hidróxido de sódio $(\mathrm{NaOH}) 1,0 \mathrm{~N}(1: 5(\mathrm{p} / \mathrm{v}))$ conforme Suphantharika et al. (2003). A Espectrometria de Ressonância Magnética Nuclear do Carbono 13 do polímero extraído, realizada pela Universidade Federal do Paraná revelou composição exclusiva de glicose, com $66 \%$ das moléculas ligadas em $\beta(1-3)$ e $33 \%$ em $\beta(1-6)$. A carboximetilação da $\beta$-glucana insolúvel foi conduzida pela adição, sob agitação lenta, de isopropanol e $\mathrm{NaOH} 30 \%$, e em seguida de ácido monocloroacético. Feito isso o material foi mantido a $65^{\circ} \mathrm{C}$, sob agitação de $70 \mathrm{rpm}$, durante 5 horas. A solução resultante foi filtrada e os sólidos lavados sucessivamente com Metanol : Ácido acético (7:3), Metanol : Água (4:1), Metanol e Acetona . $\mathrm{O}$ precipitado foi dializado contra água destilada, a $4^{\circ} \mathrm{C}$, durante 48 horas. Após a diálise a CMG diluída em água foi mantida sob refrigeração para posterior adição na ração das aves. Uma amostra de CMG foi liofilizada para a determinação da Composição Centesimal.

\section{Parâmetros Zootécnicos}

As propriedades imunoestimulantes da $\mathrm{CMG}$ foram avaliadas em 192 pintinhos machos da linhagem COBB, divididos em 2 lotes iguais de criação. Em cada lote, os 96 animais foram pesados, distribuídos em 12 boxes com 8 aves e alimentados com rações experimentais formuladas conforme Rostagno et al. (2005) (Tabela 1) e adicionadas da farinha de milho com $0,025 \%, 0,050 \%$ e $0,075 \%$ de CMG. O grupo controle recebeu a mesma formulação, porém sem a adição da farinha de milho com CMG. Água e ração foram disponibilizadas aos animais sem restrição e cada concentração de CMG foi avaliada em triplicata, ou seja, em 3 boxes distintos de 8 aves cada. Todas as aves foram imunizadas contra a Doença de Newcastle. Em cada tratamento, à exceção do grupo controle, foram escolhidas aleatoriamente e identificadas 3 aves, que receberam $\mathrm{CMG}(\mu \mathrm{g})$ em adjuvante quil-A $(\mathrm{mL})$ via intramuscular, nas concentrações de 100 $\mu \mathrm{g} / \mathrm{mL}, 250 \mu \mathrm{g} / \mathrm{mL}$ e $250 \mu \mathrm{g} / \mathrm{mL}$, no $3^{\circ}, 7^{\circ}$ e $14^{\circ}$ dia, respectivamente.

O desempenho animal foi avaliado considerando o peso individual no início e final de cada período experimental, bem como o consumo e sobras de ração nos 12 boxes durante os 21 de experimento. A conversão alimentar foi calculada a partir dos dados de ingestão alimentar e ganho de peso individual. $\mathrm{O}$ número de aves mortas foi apontado para o cálculo da viabilidade durante os períodos experimentais. A bursa de Fabricius foi coletada para avaliação do desenvolvimento, calculado pela comparação do peso relativo dos órgãos dos grupos que consumiram ração adicionada de CMG com o grupo controle. Porções intestinais das aves dos diferentes tratamentos com CMG foram coletadas, fixadas em Bouin durante 24h, lavadas e mantidas em álcool $70 \%$ até o preparo das lâminas para histologia (BEÇAK; PAULETE, 1976). Para as análises histológicas foram consideradas as medidas da altura das vilosidades intestinais, realizadas com a auxílio do programa Motic Images Plus 2.0, utilizando câmera Moticam 2000, 2.0M Pixel (USB 2.0). 
Tabela 1. Composição nutricional das rações pré-inicial e inicial, conforme Rostagno et al. (2005), adicionadas de farinha de milho com diferentes concentrações de Carboximetilglucana $(\mathrm{CMG})$ que foram disponibilizadas para aves da linhagem $\mathrm{COBB}$ do $1^{\circ}$ ao $21^{\circ}$ dia.

\begin{tabular}{lll}
\hline & Fases (dias) & \\
\cline { 2 - 3 } Ingrediente (\%) & $\begin{array}{l}\text { Pré-inicial } \\
(\mathbf{1 - 7 )}\end{array}$ & $\begin{array}{c}\text { Inicial } \\
\mathbf{( 8 - 2 1 )}\end{array}$ \\
\hline Milho & 56,12 & 57,42 \\
Farelo de soja & 36,62 & 34,74 \\
Óleo de soja & 2,72 & 3,72 \\
Fosfato bicálcio & 1,92 & 1,82 \\
Calcário & 0,86 & 0,83 \\
Suplemento Vit-mineral ${ }^{\mathrm{a}}$ & 0,5 & 0,50 \\
Sal comum & 0,46 & 0,45 \\
L-Lisina HCL & 0,42 & 0,25 \\
DL-Metionina & 0,38 & 0,27 \\
\hline Total & $\mathbf{1 0 0 , 0 0}$ & $\mathbf{1 0 0 , 0 0}$ \\
\hline & & \\
\hline Presente na formulação & & 21,14 \\
\hline Proteína bruta (\%) & 22,11 & 3050 \\
Energia metabolizável aparente (Kcal/kg) & 2960 & 0,89 \\
Cálcio (\%) & 0,94 & 0,44 \\
Fósforo disponível (\%) & 0,47 & 1,18 \\
Lisina digestível (\%) & 1,36 & 0,84 \\
Metionina + cistina digestível (\%) & 0,96 & 0,56 \\
Metionina digestível (\%) & 0,68 & 0,21 \\
\hline Sódio (\%) & 0,22 & \\
\hline
\end{tabular}

${ }^{a}$ Composição em miligramas por quilograma do premix inicial: Vitamina (Vit) E, 2.133,33; Vit B1, 1.486,33; Vit B2, 1.066,66; Vit B6, 280,50; Vit B12, 2.666,66; Vit K,3 537,33; Pantotenato de cálcio, 2.153,33; Niacina, 5.341,00; Acido fólico, 66,66; Biotina, 3,33; Colina, 74.666,66; Metionina, 322.575,00; Lisina, 122.500,00; Zinco, 10.208,23; Ferro, 7.000,00; Cobre, 1.500,00; Manganês, 11.625,00; Cobalto, 33,33; Iodo, 162,50; Selênio, 50,00; Antioxidante, 2.666,66. Vit A e Vit D3 presentes em quantidades de 2.400,00 UI/g; e 671,66 UI/g, respectivamente.

\section{Parâmetros Imunológicas}

A contagem leucocitária diferencial foi realizada em esfregaço sanguíneo, em lâminas coradas com Giemsa, ao microscópio óptico (1000x). A proporção de linfócitos, heterófilos e monócitos foi calculada em cada 100 células contadas. Os níveis de anticorpos no soro dos animais dos diferentes tratamentos com CMG na ração, e dos que receberam $\mathrm{CMG}$ via intramuscular foram mensurados em comparação ao soro das aves de 1 dia, utilizado como controle positivo. Para tanto foi empregada a técnica de Imunodifusão Radial Simples proposta por Hudson (1989), que utiliza soro de coelho IgG anti-IgY como antígeno para a quantificação do total de anticorpos (IgY) no soro das aves. A detecção de anticorpos específicos contra Newcastle foi realizada por ELISA conforme instruções do fabricante (Synbiotics Corporation).

\section{Análises Estatísticas}

Foram realizadas análises de variância e de regressão, com auxílio do programa SAEG, aplicando-se o teste $\mathrm{F}(\mathrm{p}<0,05)$ e comparandose as médias das variáveis do tratamento controle com cada tratamento de CMG. O teste de Dunnett foi empregado para a comparação da média do tratamento de CMG via intramuscular com as médias do controle e dos tratamentos da CMG na ração. 


\section{Resultados e discussão}

As médias do desempenho das aves alimentadas com a CMG obtida da $\beta$-glucana de $S$. cerevisiae, correspondentes aos 2 lotes de criação e períodos experimentais de 1 a 7 dias e 1 a 21 dias estão apresentadas na (Tabela 2). A análise de variância não revelou diferenças significativas no desempenho das aves no período de 1 a 7 dias de idade. Entretanto, foi observada diferença $(\mathrm{p} \leq 0,05)$ no ganho de peso e consumo de ração das aves suplementadas com CMG, considerando o período de 1 a 21 dias.

Tabela 2. Efeito da Carboximetilglucana (CMG) no ganho de peso (GP), consumo de ração (CR), conversão alimentar (CA) e viabilidade de frangos de corte, linhagem COBB, no período experimental de 1 a 21 dias de idade.

\begin{tabular}{ccccccccc}
\hline & \multicolumn{2}{c}{ GP/ave (g) } & \multicolumn{2}{c}{ CR/ave (g) } & \multicolumn{2}{c}{ CA } & \multicolumn{2}{c}{ Viabilidade (\%) } \\
\hline \multirow{2}{*}{ CMG(\%) } & $\begin{array}{c}\mathbf{1} \text { a 7 } \\
\text { dias }\end{array}$ & $\begin{array}{c}\mathbf{1} \text { a 21 } \\
\text { dias }\end{array}$ & $\begin{array}{c}\mathbf{1} \text { a 7 } \\
\text { dias }\end{array}$ & $\begin{array}{c}\mathbf{1} \text { a 21 } \\
\text { dias }\end{array}$ & $\begin{array}{c}\mathbf{1} \text { a 7 } \\
\text { dias }\end{array}$ & $\begin{array}{c}\mathbf{1} \text { a 21 } \\
\text { dias }\end{array}$ & $\begin{array}{c}\text { 1 a 7 } \\
\text { dias }\end{array}$ & $\begin{array}{c}\mathbf{1} \text { a 21 } \\
\text { dias }\end{array}$ \\
\hline 0 & 93,36 & 585,41 & 148,50 & 846,92 & 1,60 & 1,45 & 100,00 & 100,00 \\
0,025 & 95,78 & 636,10 & 153,06 & 908,82 & 1,60 & 1,43 & 97,92 & 95,83 \\
0,050 & 89,17 & 611,43 & 149,90 & 878,23 & 1,71 & 1,44 & 100,00 & 100,00 \\
0,075 & 99,56 & 627,30 & 156,78 & 896,23 & 1,58 & 1,43 & 93,75 & 93,75 \\
\hline CV $(\%)$ & 8,023 & 4,044 & 3,943 & 3,599 & 7,386 & 2,468 & 4,311 & 4,617 \\
Efeito & $\mathrm{ns}$ & $\mathrm{C}^{\mathbf{1}}$ & $\mathrm{ns}$ & $\mathrm{C}^{\mathbf{2}}$ & $\mathrm{ns}$ & $\mathrm{ns}$ & $\mathrm{ns}$ & $\mathrm{ns}$ \\
\hline
\end{tabular}

$\mathrm{ns}=$ não significativo

$1-\mathrm{C}=$ efeito cúbico $(\mathrm{p} \leq 0,05) ; \mathrm{Y}=585,407+5,08060 \mathrm{x}-0,153025 \mathrm{x}^{2}+0,00123643 \mathrm{x}^{3}\left(\mathrm{R}^{2}\right.$ do modelo 1,00$)$

$2-\mathrm{C}=$ efeito cúbico $(\mathrm{p} \leq 0,05) ; \mathrm{Y}=846,922+6,20684 \mathrm{x}-0,1186855 \mathrm{x}^{2}+0,00150484 \mathrm{x}^{3}\left(\mathrm{R}^{2}\right.$ do modelo 1,00$)$

Os resultados no presente estudo estão de acordo com o relatado em estudos semelhantes realizados com polissacarídeos imunoestimulantes. Guo, Ali e Qureshi (2003) testou diferentes níveis $(0,05 \%$; $0,1 \% ; 0,2 \% ; 0,3 \%$ e $0,4 \%$ ) de extrato de Lentinula edodes, em substituição ao antibiótico na dieta de frangos de corte, e observou que o maior ganho de peso e a melhor conversão alimentar foram obtidos com o nível de $0,2 \%$ de extrato de cogumelo. Fuini (2001) avaliou o efeito de um extrato de Agaricus blazei, sabidamente composto de $\beta$-glucana, nos níveis $0,25 \% \quad 0,50 \% \quad 0,75 \%$ e $1,00 \%$ na dieta de aves de corte e verificou que o nível de $0,25 \%$ possibilitou o maior ganho de peso e a melhor conversão alimentar.

$\mathrm{Na}$ (Tabela 3) estão demonstradas as médias calculadas para a altura de vilosidades do intestino delgado das aves alimentadas com CMG aos 21 dias de idade. Foram observadas diferenças $(p<0,01)$ entre a altura das vilosidades do duodeno e jejuno das aves tratadas com CMG e o grupo controle. No jejuno, a medida da altura das vilosidades das aves tratadas foi maior do que o grupo controle. Supostamente, este aumento nas vilosidades pode ter influenciado no melhor ganho de peso das aves tratadas com CMG.

Tabela 3. Medidas da altura, em $\mu \mathrm{m}$, das vilosidades do intestino delgado de frangos de corte, linhagem COBB, de 21 dias de idade alimentados com ração suplementada com diferentes níveis de Carboximetilglucana (CMG).

\begin{tabular}{lll}
\hline CMG (\%) & Duodeno $^{\mathbf{1}}(\boldsymbol{\mu m})$ & Jejuno $^{2}(\boldsymbol{\mu m})$ \\
\hline 0 & 1873,67 & 898,52 \\
0,025 & 1491,07 & 1166,54 \\
0,050 & 1396,78 & 927,03 \\
0,075 & 1644,02 & 1024,54 \\
\hline CV $(\%)$ & 12,152 & 16,684 \\
Efeito & $\mathrm{Q}$ & $\mathrm{C}$ \\
\hline
\end{tabular}

$1-\mathrm{Q}=$ efeito quadrático $(\mathrm{p}<0,01) ; \mathrm{Y}=1877,15-21,9136 \mathrm{x}+0,250054 \mathrm{x}^{2}\left(\mathrm{R}^{2}=1,00\right)$

$2-\mathrm{C}=$ efeito cúbico $(\mathrm{p}<0,01) ; \mathrm{Y}=898,520+32,1320 \mathrm{x}-1,08167 \mathrm{x}^{2}+0,00900857 \mathrm{x}^{3}\left(\mathrm{R}^{2}=1,00\right)$ 
Não foram encontradas diferenças entre o peso da bursa de Fabrícius das aves alimentadas com os diferentes níveis de CMG e do grupo controle (Tabela 4). Entretanto, foi observada uma tendência ao aumento do peso relativo deste órgão nos animais suplementados com 0,025 e $0,050 \%$ de $\mathrm{CMG}$ em relação ao grupo controle. Em seu estudo Guo, Ali e Qureshi (2003) constatou que o peso relativo da bursa em frangos suplementados com 0,002\% e $0,004 \%$ de $\beta$-glucana, aos 14 dias de idade, foi superior ao do grupo controle. O aumento no peso do órgão linfóide primário pode ser uma evidência da maturação de um número maior de linfócitos $\mathrm{T}$ (CD4 e CD8), indiretamente de linfócitos B e, através destes, a produção de anticorpos, sugerindo que aves tratadas com CMG têm melhor desenvolvimento da imunidade adaptativa. Os valores correspondentes à proporção de células fagocíticas, calculados na contagem leucocitária diferencial, estão expressos no (Gráfico 1).

Tabela 4. Peso relativo da bursa de Fabrícius de frangos de corte, linhagem COBB aos 21 dias de idade, alimentados com ração suplementada com diferentes níveis de Carboximetilglucana (CMG).

\begin{tabular}{llll}
\hline CMG (\%) & Peso corporal (g) & Peso bursa (g) & Peso relativo bursa (\%) \\
\hline 0 & 723,50 & 1,99 & 0,275 \\
0,025 & 805,00 & 2,36 & 0,293 \\
0,050 & 790,17 & 2,49 & 0,316 \\
0,075 & 768,67 & 1,92 & 0,250 \\
\hline CV (\%) & - & - & 24,861 \\
Efeito & - & - & $\mathrm{ns}$ \\
\hline
\end{tabular}

ns = não significativo

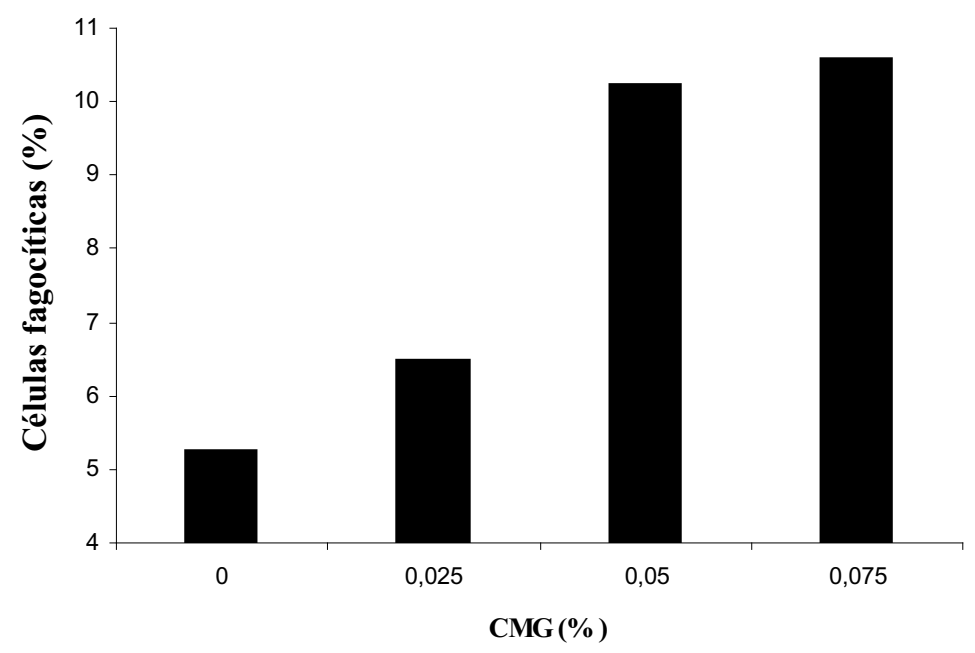

Gráfico 1. Efeito de diferentes níveis de Carboximetilglucana (CMG) de Saccharomyces cerevisiae adicionada a ração de frangos de corte da linhagem COBB no número de células fagocíticas, aos 21 dias de idade. 
Os resultados da contagem leucocitária diferencial aos 21 dias revelaram aumento na proporção das células fagocíticas, os heterófilos e monócitos, para os diferentes níveis de suplementação com CMG. As aves alimentadas com ração contendo $0,050 \%$ e $0,075 \%$ de CMG tiveram acréscimo de 95,24\% e $101,59 \%$ na porcentagem de células fagocíticas, respectivamente, em relação ao grupo controle. De acordo com Estrada, Van Kessel e Laarveld (1999) o aumento no número de células fagocíticas pode ser explicado por mecanismos homeostáticos da resposta imune inata. Através destes mecanismos indivíduos com imunossupressão tendem a mudar seu estado elevando os níveis dessas células sanguíneas, permitindo ao organismo uma melhor resposta imunológica frente a uma infecção. Neste contexto, é sabido que a $\beta$-glucana da parede celular de $S$. cerevisiae, e seus derivados, como a $\mathrm{CMG}$, atuam na ativação da resposta inflamatória, particularmente ampliando a função das células fagocíticas (HUFF et al., 2006).

Os resultados encontrados no presente estudo corroboram com aqueles relatados por Thanardkit et al. (2002), que ao alimentarem camarões com $0,2 \%$ de $\beta$-glucana, durante 3 dias, constataram multiplicação das células de defesa com aumento da atividade bactericida.Uma melhor resposta na atividade fagocítica também foi relatada por Guo, Ali e Qureshi (2003), em aves suplementadas com
$0,002 \%$ e $0,004 \%$ de $\beta$-glucana, onde os macrófagos fagocitaram maior número de antígenos, em comparação àqueles do sangue de aves do grupo controle. Lowry et al. (2005) isolaram heterófilos de aves imaturas desafiadas com Salmonella enterica, suplementadas com $\beta$-glucana e relataram que a habilidade fagocítica, estava relacionada ao aumento na liberação de radicais livres. Com a ativação e recrutamento dos heterófilos das aves, a $\beta$-glucana pode proporcionar uma ação mais eficaz na fagocitose e eliminação de patógenos.

A(Tabela 5) mostra as médias relativas aos efeitos da CMG via oral sobre os níveis de anticorpos totais e específicos, encontrados no soro das aves de 21 dias, do primeiro lote de criação. A concentração de IgY no soro dos frangos suplementados com CMG aumentou $(p<0,01)$ em comparação ao grupo controle. Com um dia de vida, os pintinhos são dependentes, para proteção humoral, dos níveis de anticorpos maternos depositados no conteúdo vitelínico e apresentam altos índices de IgY em seu soro, porém não possuem capacidade de produzi-los. Aos 21 dias, com redução dos anticorpos maternos, os níveis de IgY encontrados nos frangos de corte foram aumentados pela suplementação com CMG na ração. Em seu estudo, Guo, Ali e Qureshi (2003) relatou que a suplementação da ração com $0,002 \%$ e $0,004 \%$ de $\beta$-glucana de $S$. cerevisiae aumenta os níveis de IgY no soro de frangos, e eleva a resposta secundária de anticorpos totais.

Tabela 5. Efeito da suplementação de Carboximetilglucana (CMG) via oral na alimentação de frangos de corte aos 21 dias de idade, linhagem COBB, sobre a produção de anticorpos totais e específicos para Newcastle.

\begin{tabular}{lll}
\hline CMG (\%) & $\mathbf{I g Y}^{\mathbf{1}}(\mathbf{m g} / \mathbf{m L})$ & Título* $^{*}$ \\
\hline 0 & 1,422 & 0,264 \\
0,025 & 1,680 & 0,267 \\
0,050 & 1,854 & 0,305 \\
0,075 & 1,982 & 0,353 \\
$\mathrm{CP}^{* *}$ & 2,386 & 1,334 \\
\hline CV $(\%)$ & 29,447 & 63,670 \\
Efeito & $\mathrm{L}$ & $\mathrm{ns}$ \\
\hline
\end{tabular}

*Título dos anticorpos específicos para Newcastle

$1-\mathrm{L}=$ efeito linear $(\mathrm{p}<0,01) ; \mathrm{Y}=1,45622+0,00741836 \mathrm{x}\left(\mathrm{R}^{2}=0,98\right) . \mathrm{ns}=$ não significativo

$* * \mathrm{CP}=$ Aves de 1 dia de idade (controle positivo) 
Nos animais que receberam a $\mathrm{CMG}$ via intramuscular, a concentração de $\operatorname{IgY}$ diferiu significantemente daquela observada para as aves alimentados com CMG, exceto quando suplementadas com $0,025 \%$, e aumentou somente em relação ao grupo de aves em dieta sem adição de CMG. Estes resultados sugerem que a concentração de CMG aplicada via intramuscular não foi suficiente para aumentar os anticorpos totais sendo, ineficaz na resposta imune humoral não específica. De acordo com Sakurai et al. (1997) a administração intravenosa de $\beta$-glucana e de seus derivados solúveis, em concentração mais elevada que aquela aplicada no presente estudo, pode ativar a secreção de óxido nítrico pelos macrófagos e elevar a concentração de interferon $\gamma$.

Não foi observada diferença entre os níveis de anticorpos específicos para Newcastle dos grupos suplementados com as diferentes concentrações de CMG e destes comparados ao controle (Tabela 5). Entretanto, o título de anticorpos aumentou com o acréscimo da concentração de CMG na ração, com elevação de até 33,8\% para o grupo suplementado com $0,075 \%$ em relação ao grupo controle. Os valores elevados de título encontrados em pintinhos com 1 dia de idade podem ser explicados pela passagem de anticorpos específicos para Newcastle pelas matrizes vacinadas.

Para os animais que receberam as três doses de CMG via intramuscular foi observado, pelo teste de Dunnet, aumento dos anticorpos específicos em relação a todas as aves alimentadas com CMG. Em comparação ao grupo controle, o acréscimo no título foi de 53,16\%. A melhora na resposta imunológica pelo aumento nos níveis de anticorpos específicos está relacionada à vacinação que promove ativação de linfócitos $\mathrm{B}$ através da interação de seus receptores antigênicos com $\mathrm{O}$ antígeno da própria vacina. Neste aspecto, inúmeros estudos científicos já demonstraram a habilidade da $\beta$-glucana em potencializar respostas específicas e não específicas de anticorpos. Conforme Kubala et al. (2003) a imunomodulação exercida pelas glucanas é decorrente de sua ligação a receptores de superfície em células do sistema imune, que uma vez estimuladas podem ativar de rotas de sinais intracelulares que culminam em respostas imunoregulatórias.

\section{Conclusão}

Os resultados obtidos com a adição da $\mathrm{CMG}$ à ração das aves de corte, da linhagem $\mathrm{COBB}$, até o $21^{\circ}$ dia de idade, indicam uma melhora no sistema imune inato, com o aumento das células fagocíticas, e do sistema imune humoral, através de elevação da concentração de imunoglobuinas totais e do título de anticorpos específicos. Provavelmente, sendo uma molécula solúvel, a CMG exibiu melhor atividade imunomodulatória pela via intramuscular, entretanto, a possibilidade de efeitos adversos deve ser considerada com cuidado, pois trata-se de uma molécula grande, de forma que a administração oral pode representar a melhor opção.

\section{Referências}

ASSOCIAÇÃO BRASILEIRA DOS PRODUTORES E EXPORTADORES DE FRANGO - ABPEF. Mercado interno e exportações. 2009. Disponível em: <www.abef. com.br:80/noticias>. Acesso em: 20 nov. 2009.

BEÇAK, W. S., PAULETE J. Técnicas de citologia $e$ histopatologia. Rio de Janeiro: Livros Técnicos e Científicos, 1976. 305 p. v. 1.

BROWN, G. D.; GORDON, S. Fungal beta-glucans and mammalian immunity. Immunity, Massachusetts, v. 19, n. 3, p. 311-315, 2003.

CHENG, Y. H.; LEE, D. N.; WEN, C. M.; WENG. C. F. Effects of beta-glucan supplementation on lymphocyte proliferation,macrophage chemotaxis and specific immune responses in broilers. Asian Australasian Journal of Animal Sciences, Austrália, v. 17, n. 8, p. 1145-1149, 2004.

DIONIZIO, M. A. BERTECHINI, A. G.; KATO, R. K.; TEIXEIRA, A. S. Prebióticos como promotores de crescimento para frangos de corte - desempenho e rendimento da carcaça. Ciências Agrotécnicas, Lavras, p. 1580-1587, dez. 2002. Edição Especial. 
EDQVIST, L. R.; PEDERSEN, K. B. Antimicrobials as growth promoters: resistance to common sense. In: EUROPEAN ENVIRONMENT AGENCY. Late lessons from early warnings: the precautionary principle 1896-2000. Copenhagen, OPOCE, 2002. Disponível em: $\quad<$ http://reports.eea.eu.int/environmental_issue report_2001_22/en/issue-22-part-9.pdf>. Acesso em: 13 maio 2008.

ESTRADA, A.; VAN KESSEL, A.; LAARVELD, B. Effect of administration of oat $\beta$-glucan on immune parameters of healthy and immunosuppressed beef steers. Canadian Journal of Veterinary Research, Canadá, v. 63, n. 4, p. 261-268, 1999.

FUINI, M. G. Utilização do cogumelo Agaricus blazei como alternativa ao uso de antibióticos em rações para frangos de corte. 2001. Dissertação (Mestrado em Zootecnia) - Universidade Federal de Lavras, Lavras.

GUO, Y.; ALI, R. A.; QURESHI, M. A. The influence of $\beta$-glucan on immune responses in broiler chicks. Immunopharmacology and Immunotoxicology, Austrália, v. 25 , n. 3 , p. $461-427,2003$.

HUDSON, L.; HAY, F. C. Practical immunology: antibody interaction with antigen. 3. ed. Oxford: Blackwell Scientific Publications, 1989.

HUFF, G. R.; HUFF, W. E.; RATH, N. C.; TELLEZT, G. Limited treatment with $\beta-1,3 / 1,6$-glucan improves production values of broiler chickens challenged with Escherichia coli. Poultry Science, Califórnia, v. 85, n. 4, p. 613-618, 2006.

KIM, S. Y.; SONG, H. J.; LEE, Y. Y.; CHO, K. H.; $\mathrm{ROH}, \mathrm{Y}$. K. Biomedical issues of dietary fiber $\beta$-glucan. Journal Korean of Medical Science, Coréia, v. 21, p.781789, 2006.

KLIS, F. M.; MOL, P.; HELLINGWERF, K.; BRUL, S. Dynamics of cell wall structure in Saccharomyces cerevisiae. FEMS Microbiology Reviews, Oxford, v. 26, n. 3, p. 239-256, 2002.

KO, Y. T.; LIN, Y. L. 1,3- $\beta$-Glucan quantification by a fluorescence microassay and analysis of its distribution in foods. Journal of Agricultural and Food Chemistry, Washington, v. 52, n. 11, p. 3313-3318, 2004.

KUBALA, L.; RUZICKOVA, J.; NICKOVA, K.; SANDULA, J.; CIZ, M.; LOJEK, A. The effect of $(1 \rightarrow 3)$ $\beta$-D-glucans, carboxymethylglucan and schizophyllan on human leukocytes in vitro. Carbohydrate Research, Amsterdan, v. 338, n. 24, p. 2835-2840, 2003.
LOWRY, V. K.; FARNELL, M. B.; FERRO, P. J.; SWAGGERTY, C. L.; BAHJ, A.; KOGUT, M. H. Purified $\beta$-glucan as an abiotic feed additive up-regulates the innate immune response in immature chickens against Salmonella enterica serovar Enteritidis. International Journal of Food Microbiology, Amsterdan, v. 98, n. 3, p. 309-318, 2005.

MACHADO, A. M. B.; DIAS, E. S.; SANTOS, E. C.; FREITAS, R. T. F. Composto exaurido do cogumelo Agaricus blazei na dieta de frangos de corte. Revista Brasileira de Zootecnia, Viçosa, v. 36, n. 4, p. 1113-1118, 2007.

ROSTAGNO, H. S.; ALBINO, L. F. T.; DONZELE, J. L. GOMES, P. C.; FERREIRA, S. A.; OLIVEIRA, R. F.; LOPES, D. C. Tabelas brasileiras para aves e suinos: composição de alimentos e exigências nutricionais. 2. ed. Viçosa: UFV, Departamento de Zootecnia, 2005.

SAKURAI, T.; KAISE, T.; YADOMAE, T.; MATSUBARA, C. Different role of serum components and cytokines on alveolar macrophage activation by soluble fungal $(1 \rightarrow 3)-\beta$-D-glucan. European Journal of Pharmacology, Amsterdan, v. 334, n. 2-3, p. 255-263, 1997.

SILVA, E. N.; TEIXEIRA, A. S.; BERTECHINI, A. G.; FERREIRA, C. L. L. F.; VENTURA, B. Desempenho de frangos de corte alimentados com rações contendo probióticos, antibióticos e duas fontes de fósforo. Ciências Agrotecnicas, Lavras, v. 24, p. 225-232, dez. 2000. Edição Especial.

SUPHANTHARIKA, M.; KHUNRAE, P.; THANARDKIT, P.; VERDUYN, C. Preparation of spent brewer's yeast $\beta$-glucans with a potential application as an immunostimulant for black tiger shrimp, Penaeus monodon. Bioresource Technology, Amsterdan, v. 88, n. 1, p. 55-60, 2003.

THANARDKIT,P.;KHUNRAE,P.;SUPHANTHARIKA, M.; VERDUYN, C. Glucan from spent brewer's yeast: preparation, analysis and use as a potential immunostimulant in shrimp feed. World Journal of Microbiology and Biotechnology, Netherlands, v. 18, n. 6, p. 527-539, 2002.

TZIANABOS, A. O. Polysaccharide immunomodulators as therapeutic agents: structural aspects and biologic function. Clinicalof Microbiology Reviews, Washington, v.13, n. 4, p. 523-533, 2000. 
